\title{
Measuring Significant Learning through a Personal Leadership Transformation Assignment in an Undergraduate Leadership Course
}

\author{
Summer F. Odom \\ Assistant Professor \\ Department of Agricultural Leadership, Education, \& Communications \\ Valerie McKee \\ Leadership Programs Coordinator \\ UF/IFAS Center for Leadership \\ Allison L. Dunn \\ Ph.D. Student \\ Department of Agricultural Leadership, Education \& Communications
}

\begin{abstract}
Leadership educators should strive to promote deeper learning within their students. Fink's $(2003,2013)$ taxonomy of significant learning is a framework for intentionally grounding leadership curricula in the principles and practices of evidence-based learning. The purpose of this study was to measure undergraduate students' significant learning after the completion of a PLTA in a personal leadership course and reflection about the experience. A content analysis of 24 student reflections was used to analyze the six domains of learning: foundational knowledge, application, integration, human dimension, caring, and learning how to learn. Evidence of all six domains of learning were found within the student reflections and it was observed that students who had definite contexts in which to apply and well-defined goals for the assignment could better articulate their learning.
\end{abstract}

\section{Introduction \& Background}

Leadership educators commonly understand the value of engaging pedagogy and active learning strategies in the classroom (Jenkins, 2012). This is evident in leadership education's wide use of active learning techniques such as case studies, debates, role-playing, problem-based learning, small group activities, simulations, and community engagement within a broad range of leadership development programs. However, as the complexity of higher education increases and as student populations become more diverse, it is necessary for leadership educators to reexamine the active learning strategies and techniques used in their classrooms if they are to enhance leadership learning, as engaged pedagogies may apply differently to students from diverse backgrounds or experiences (Owen, 2015a; Roberts, 2007).

Furthermore, as the problems leaders are called upon to solve grow in complexity and interdisciplinary nature, the field of leadership education needs to undergo a transformation "where powerful pedagogies and emerging knowledge about the scholarship of teaching and learning" are utilized (Owen, 2015a, p. 7). Incorporating integrative approaches tolearning 
enables students to "think the world together [rather] than think it apart" (Palmer \& Zajonc, 2010, p. 22). Integrated learning is more than merely making connections between disciplines. Rather, it is the ability to synthesize and apply what was learned into new contexts (Owen, 2015a). Thus, in an integrated learning environment, the curricular, co-curricular, and extracurricular experiences are not separated, but are valued equally.

Encouraging students to consistently integrate their leadership learning experiences in their daily lives can be challenging; especially if the students have been exposed to competing or conflicting views towards leadership. However, utilizing integrative learning principles to leverage academic challenge, the interaction of faculty and students, and active, collaborative learning opportunities provides opportunities for students to overcome this challenge (Owen, 2015b). When faculty intentionally include the five hallmarks of integrative learning within a leadership course, students are exposed to a model whereby they can develop and refine their ability to integrate leadership concepts into other aspects of their lives, thereby deepening their learning.

Owen (2015b) noted that the first hallmark of integrative learning is connections to experience. Finding ways for students to synthesize experiences outside the classroom with the content in the classroom enables students to deepen their understanding of both the experience and the course content. A second hallmark is enabling students to make connections across disciplines. Leadership is a dynamic and interdisciplinary endeavor; therefore, students must be able to combine information and content between classes/disciplines in order to know when and how to adapt their leadership approach effectively. Being able to adapt and apply what was learned in one context to another, or transfer, is the third hallmark of integrated learning. For transfer to occur, an experience cannot be limited only to the experienced context. Rather, students should be encouraged to draw from all of their experiences as they problem solve or confront complex issues. Integrated communication, or the ability to effectively communicate across formats and with diverse audiences or in diverse contexts, is key as the world becomes more interconnected and the speed of change increases. The fifth hallmark is reflection and selfassessment. Students need to understand that leadership development is a life-long process and necessitates being able to recognize the need for change as well as continual learning and development (Owen, 2015b).

Leadership educators, as well as students, share the responsibility to create effective leadership learning environments (Roberts, 2007). In these environments, the focus turns from the leadership theories themselves to the process students use to learn the theories. Though efforts have been made to ground leadership in learning (Brungardt, 1997; Daloz Parks, 2005; Day, Harrison, \& Halpin, 2009; Preskill \& Brookfield, 2009; Roberts, 2007; Vaill, 1998) and multi-institutional research examining the influence of experiences and education in developing leadership has been done, limited research exists detailing the programs that apply these evidence-based practices. Consequently, leadership educators should strive to promote and research deeper learning-focused classroom approaches, as there is evidence that deeper learning will foster deeper leadership competency and capacity (Roberts, 2007).

One way to engage in deeper learning is the use of active learning techniques paired with personal and shared reflection. Because of these integrative learning approaches and engaging 
techniques, leadership educators are able to cultivate learning environments that help students effectively integrate knowledge, skills, and experiences (Owen, 2015a). Furthermore, active learning techniques should be considered levers of learning and that "they might apply differentially to students with diverse backgrounds and prior experiences" (Owen, 2015a,p.9). As a result, it is recommended that active learning techniques be intentionally used "to gauge learning in formative (i.e., during the process) and summative ways (at the end of the experience)" (Owen, 2015a, p. 9).

Yet, utilizing active learning techniques in a classroom is not enough. Students must also learn to take ownership of their own education and become self-directed learners. To become self-directed learners, students must learn to "assess the demands of the task, evaluate theirown knowledge and skills, plan their approach, monitor their progress, and adjust their strategies as needed" (Ambrose, Bridges, DiPietro, Lovett, \& Norman, 2010, p. 191). As students progress through higher levels of education and into their professional lives, having the skills to be a selfdirected learner becomes increasingly important as students take on more complex tasks and are expected to accept greater responsibility for their own learning. According to Ambrose et al. (2010), there are five student stages within the cycle of self-directed learning. First, students must learn to fully assess the task at hand, including any major goals or constraints. Equipped with this understanding, students move on to evaluate their own knowledge and skills as well as any strengths or weaknesses they may personally have that would affect their work. Then, selfdirected students plan their approach to the task in such a way that accounts for the current situation. To enact their plan, students proceed to applying various strategies as they monitor their personal progress. Lastly, self-directed students take the time to reflect on the degree to which their current approach is working; this stage can lead to adjusting the plan and restarting the cycle.

As research relating types of learning in an academic leadership context is limited, this study was an opportunity to expand the current literature. The active learning experience of a personal leadership transformation assignment (PLTA) in an undergraduate leadership course was used to describe the types of learning the students experienced throughout the three weeks of the assignment. This research study was designed to address the Association of Leadership Educator's National Leadership Education Research Agenda Priority I (Andenoro, Allen, HaberCurran, Jenkins, Sowcik, Dugan, \& Osteen, 2013). By focusing curriculum development frameworks to enhance the transfer of learning, leadership educators are better able to explore the developmental nature of leadership (Andenoro et al., 2013).

\section{Theoretical Framework}

Traditionally, educators have turned to the cognitive domain of Bloom's (1956) taxonomy to formulate course work and measure student learning; this domain lists six kinds of learning arranged in a hierarchical sequence: Evaluation, Synthesis, Analysis, Application, Comprehension, and Knowledge. While the value of Bloom's (1956) taxonomy remains unquestioned, it may be difficult to apply all six kinds of learning identified in the taxonomy's cognitive domain to the goals and priorities of leadership education specifically in the areas of learning how to learn, ethics, communication skills, character, ability to adapt to change, and leadership and interpersonal skills (Fink, 2003). 
As an alternative to Bloom's taxonomy, Fink's (2013) taxonomy offers a clear guide for leadership educators to intentionally ground their curricula in the principles and practices of evidence-based learning. The taxonomy is based on the belief that for learning to occur, change must also occur within the learner (Fink, 2003). Unlike Bloom's (1956) taxonomy, Fink's (2013) taxonomy is not hierarchical but interactive and relational in nature, resulting in a synergistic approach to learning. Practitioners of evidence-based learning can use the taxonomy to evaluate their lessons and programs. Fink's (2013) taxonomy includes six domains that may work together to promote significant learning: foundational knowledge, application, integration, human dimension, caring, and learning how to learn. Each domain is discussed below.

Foundational knowledge is defined as the "basic understanding that is necessary for other kinds of learning" (Fink, 2003, p. 31), and provides the footing upon which other learning and knowledge is built. In order to learn new concepts, students must have the ability to understand and remember specific information and concepts (Fink, 2003). Consequently, it is important for students today to have some basic working knowledge of the general fields of study, such as science, history, mathematics, and geography; however, students should also possess foundational knowledge of applied fields or perspectives, such as leadership, evolution or capitalism, as the world and the problems students face become more complex and interdisciplinary in nature.

While understanding and remembering facts and ideas secures students' knowledge base, students also learn how to engage in a new kind of action, which can be intellectual, physical, or social (Fink, 2003). Application learning "allows other kinds of learning to become useful" (Fink, 2003, p. 31). Engagement in different kinds of thinking, such as critical or creative thinking, can be a valuable form of application learning. Application learning also includes the development of skills like communication, project management, or other manual skills.

Coupled with foundational knowledge and application learning is integration. Fink (2003) described integration learning as when students are able to make connections across ideas, people, and/or contexts for use in the present or the future. The act of making these new connections gives learners a new form of power, "especially intellectual power" (Fink, 2003, p. $31)$.

But learning is not just about learning or remembering facts or data. The human dimension is also significant. As students learn something new or important about themselves or others, they become prepared to function and interact with others more effectively (Fink, 2003). What is learned or how it is learned can potentially give students "a new understanding of themselves (self-image) or a new vision of what they want to become (self-ideal)" (Fink, 2003, p. 31). Furthermore, the discovered social and personal implications of learning about others can influence students' interpersonal relationships. According to Fink (2003), "this kind of learning informs students about the human significance of what they are learning" (p.32).

Closely connected to the human dimension is caring. Sometimes an outcome of learning is a change in the degree to which a student cares about or finds significance in a matter, resulting in new formed feelings, interests, or values (Fink, 2003). When students care about 
something, they then have the energy they need to learn more about it and make it a part of their lives. Without this energy for learning, "nothing significant happens" (Fink, 2003, p. 32).

One's energy for learning is important as students learn the process of learning. All students do not learn in the same ways nor at the same pace. Thus, as students actively participate in the learning process in their individual studies, they gain insight and understanding into the various aspects of learning and how they learn; or in other words, they are learning how to learn for themselves (Fink, 2003). Such learning can result in the student developing selfauthorship, self-regulation, critical self-reflection, self-efficacy, resilience, adaptability, and motivation. Fink (2003) states this kind of learning "enables students to continue learning in the future and to do so with greater effectiveness" (p.32).

Fink's model posits that each learning domain is related to the other 5 learning domains. Thus, the learning is synergistic and meeting one type of learning can enhance the other types of learning. According to Fink (2003), a learning experience that promotes all six learning domains can be deemed significant. It is plausible then, that leadership educators who use a combination of significant kinds of learning will create interaction effects that enhance the achievement of overall significant learning by students. Additionally, Owen (2015a) suggests leadership practitioners could "examine their leadership curricula, programs, and initiatives to see to what extent they are addressing each of Fink's domains" (p. 12).

\section{Purpose}

The purpose of this study was to explore and describe the significant learning students experienced after the completion of a PLTA in a personal leadership course. Content analysis was completed on the students' reflective essays at the conclusion of the assignment. Fink's (2013) six domains of learning were used as the constructs for documenting the learning achieved.

\section{Methodology}

Study Context. The context of this study was an undergraduate personal leadership course taught within a 15-week semester at a four-year, public land-grant institution. The course was structured around the five practices of exemplary leaders (Kouzes \& Posner, 2014). One assignment in the course, the PLTA, consisted of choosing one of the five practices/behaviors of exemplary leaders (Kouzes \& Posner, 2014) to develop over a timespan of three weeks.

Students then engaged in activities that allowed them to focus, apply, and develop the selected practice over the three-week period. Examples of students engaging in purposeful activities to focus, apply, and develop one of the five practices included: cooking new recipes, attempting to change a flat tire (Challenge the Process), stuck notes around their daily devotionals and bathroom mirror (Enable Others to Act), encouraged family and friends to work out and led them in a workout (Inspire a Shared Vision), took a more dominant role in group discussions, prioritized important aspects of my days, took a training position at work (Model the Way), and interacted with kids at the hospital instead of by phone (Encourage the Heart). Students used Twitter to "tweet" about their practice on a daily basis, provide encouragement to classmates, 
and as a means of accountability to their classmates. At the end of the experience, students completed a reflection. The reflection consisted of the following questions: 1) questions related to specific items completed to help them develop the behavior, 2) how they measured their progress on the behavior, 3) comparing their progress over the timespan of the assignment, 4) whether or not they achieved their goals they set, 5) the role of their accountability partner, 6) their evaluation of using Twitter for self-awareness/accountability, and 7) overall what they learned. The reflections were not completed specifically for research purposes, as Bryman(2012) asserts that documents for qualitative content analysis should not "have been produced specifically for the purpose of social research" (p. 543). Reflective writing captures the thinking process as experienced by the learner. Reflection allows instructors and practitioners to get a glimpse into the knowledge gained by the participants through their experiences (Scanlon, Care, \& Udod, 2002). Narrative knowledge, which arises from reflective writing leads to individual understanding about a situation from one participant and then attempts to arrive at broader truths through examining particulars about a situation (Charon, 2001).

A purposive sample (Merriam, 2009) of reflections from students enrolled in the personal leadership course in the fall 2015 semester was chosen for this study. There were 70 students enrolled in the course. Students enrolled in the course were sophomores, juniors, and seniors either completing a degree in [leadership studies] or obtaining a leadership minor. About half of the population were male $(48.6 \% ; 34$ students) and the other half were female $(51.4 \% ; 36$ students). Each student reflection was downloaded from the online learning management system and given a code ( 1 to 70 ) as part of the audit trail. A sample of 24 reflections were chosen for review for the final data analysis $(n=24)$. To attain maximum variation in the sample (Merriam, 2009), individuals were selected to represent the population, which will be described in the rest of this paragraph. The class was divided into learning communities (four students each), and the five teaching assistants along with the instructor were each assigned to assist with two or three learning communities. To help alleviate biases from teaching assistants, the sample was taken from one learning community of each of the teaching assistants and instructor for a total of six learning communities, consisting of four students in each to arrive at the final sample of 24 student reflections. Students self-selected their learning community at the beginning of the semester. There was no attempt to obtain a representative number of females and males, academic majors or minors, or academic classification in the sample, because this would have affected the anonymity of the reflections. Codes mentioned within the findings section will reflect numbers 1-70 as the selection of the final sample was completed after the initialdownload of the students' reflections. This study was approved by the Institutional Review Board.

Research Approach and Analysis. Because this study examined indirect human behavior through an analysis of communications (reflections), content analysis was used as the methodological framework (Fraenkel, Wallen, \& Huyn, 2012). The objectives of content analysis include: 1) produce descriptive information; 2) cross-validate research findings; and 3) test hypotheses (Borg \& Gall, 1989). In this study, the researchers participated in all three. First, descriptive examples of six domains of significant learning were identified within the reflections and coded. Second, the findings were cross-validated using independent corroborative techniques. Finally, the researchers sought to test the working hypotheses that students were involved in all six types of significant learning through the course assignment. Content analysis 
allows the researcher to make inferences by examining messages through systematic and objective identification (Bryman, 2012).

Three approaches for qualitative content analysis include interpretive, social anthropological, and collaborative social research (Miles \& Huberman, 1994). This research employed a social anthropological approach. The social anthropological approach involves research in the everyday behaviors of life and the goal is to "identify and explain the ways people use or operate in a particular setting, how they come to understand things; account for, take action, and generally manage their day-to-day life" (Berg, 2001, p. 239). In this approach, individuals have spent considerable time with the participants, being involved directly or indirectly with them to understand how these individuals "interpret their social worlds (Berg, 2001, p. 239). Two of the researchers were course instructors and spent three months of prolonged engagement with the study population. This provided perspective on the reflections gathered for research and contributed to understanding how participants interpreted theirsocial world (Berg, 2001).

Sociological constructs based on the researcher's scholarly knowledge and knowledge of the substantive field of inquiry were used to examine the data (Strauss, 1987). For this study, Fink's taxonomy of significant learning (2013) was used as the sociological construct and coding scheme to add "breadth and depth to observations by reaching beyond local meanings tobroader social scientific ones" (Berg, 2001, p. 244). The unit of analysis was words, phrases, sentences, and paragraphs within the descriptive reflections. The process of identifying themes through immersion into the documents (inductive) first and then using a categorical scheme or social construct for analysis has been suggested by Abrahamson (1983). This can also be referred to as qualitative content analysis or ethnographic content analysis, which are types of content analysis that refers to an approach to analyzing documents and allows categories "to emerge out ofdata and on recognizing significance for understanding the meaning in the context in which an item being analyzed appeared" (Bryman, 2012, p. 291).

This study used an open coding technique involving carefully reading documents to determine concepts and categories (Strauss, 1987). The constant comparative method was employed allowing the researcher to integrate data (descriptive reflections) and theory (Fink's taxonomy of significant learning) using joint coding and analysis (Lincoln \& Guba, 1985). Each reflection was read by two independent reviewers and words, phrases, sentences, and paragraphs were highlighted and categorized by kind of learning. A peer debriefing with an individual not involved in the coding was conducted to check for initial categorization of units.

The trustworthiness of this study was established through Lincoln and Guba's (1985) concepts of credibility, transferability, dependability, and confirmability. Credibility was established through peer debriefing with other leadership faculty not involved in this study (Lincoln \& Guba, 1985). Researcher bias is something to consider in the credibility of qualitative research. Researchers should explain their "biases, dispositions, and assumptions regarding the research" (Merriam, 2009, p. 219). In this study, two of the researchers were instructors in the course in which reflections were completed by the participants. Because of the perceived bias of having two instructors involved in the research of their own students, a third person was brought in to analyze the data and to check for any implicit bias revelations on the part of the two 
instructors. Transferability was established through the use of maximum variation sampling and participant quotes throughout the findings of the study (Erlandson, Harris, Skipper, \& Allen, 1993); and dependability and confirmability were established through the use of audit trails, and peer audits (Lincoln \& Guba, 1985).

\section{Findings}

Participant reflections were analyzed using the framework of Fink's taxonomy of significant learning to understand how students found the personal leadership transformation experiment (PLTA) assignment to promote significant learning. Each of the kinds oflearning will be discussed using quotes from student reflections. Two additional themes emerged based on the data which provide additional information on the meaning students made from the assignment. These themes included: influence of context and influence of defined goals.

Foundational Knowledge. Foundational knowledge refers to student's ability to remember information and ideas and provides the basis for understanding other kinds of learning. Students were able to articulate what they learned from completing readings related to each of the practices. Specifically, two students reflected on the practice of encouraging the heart: "I also took away from the readings that I need to encourage others by more than a superficial complement, but encourage the ones around me with deeply thought out letters or gifts" (62). And, student 35 wrote:

From reading about Encouraging the Heart I learned that it's more than what it seems. Encouraging the Heart is never giving up, it's inspiring others to want to never give up, and we need a big strong heart to be a great leader. I learned that you must have a connection with others to make things work well. You must have connection and unity to be a good leader (35).

Another student discussed what they learned from the readings by stating "I assumed that challenging the process had to be something huge or extreme but there are small things that I could do every day that reflected a way in which I challenged the process" (4). One paragraphby a student shows how the foundational knowledge type of learning is the basis for other kinds of learning. In this instance, the student also demonstrated caring as a kind of learning:

Show them you believe. The story about Tiffany in the office was easily relatable to me as what her boss did for her is what my ag teacher did for me in high school. I never fully realized it until I read that part of the chapter, but when I did it really hit me how much my ag teacher had impacted and encouraged me. It's so easy to just recognize the things people do, not matter how small. "People need to know they matter," so that is the strategy I tried my hardest to implement (64).

Application. Students demonstrated the application domain of learning through areas of student organizations, with roommates, family and friends, work experiences, volunteer experiences, and other random areas of their life such as cooking. Some students reflected on how they applied their learning from the assignment in student organizations. One student wrote "I met face to face with members of my organization to speak to them. I came into 
conversations with specific questions that would remind the members why they are committed to [organization]" (60). And, student 35 reflected:

In [organization] I spearheaded a new idea of including the directors into the sophomore's "Lunch Buddies" so that we will be paired up with a sophomore in order to have more one on one time and get to know them. At these lunches I got to talk about their pastand what fuels their success, which was very interesting (35).

Student 4 discussed ways they practiced and applied the behavior including "... places in my life that could be improved such as my food budget and exam scores. Then I thought about ways in which I could make such improvements." Other students reflected generally about applying the practices to their work and daily actions and relationships: "I learned about the importance of connecting all of the practices together. They are individually important but when used altogether it really makes a difference in your work place or even home" (58) and

Through these reflections, we are able to chart our progress through actions we intentionally take, but are also, I've found, more susceptible to falling into reflection in other areas of our lives we didn't intend on thinking about. So now the reflection becomes twofold and we benefit in more ways than one in a reflection, [which] in my case, was a disheartening task at its launch (41).

Sometimes standing up for what you believe in is challenging, especially when it may damage current relationships with others you care about. In the end, everyone makes his or her own decisions and this must be accepted in order for everyone to move forward (27).

Integration. The integration domain of learning was demonstrated through various areas of student's lives including student organizations, everyday life occurrences, workplace, and with roommates. Three students wrote specifically about integrating the practice into their daily and weekly routines. According to student 4 "I know that in the future I will be more comfortable challenging the process and in time, with baby steps, I can find bigger ways to challenge the process, both as a leader and in my regular, everyday life" (4). And, two more quotes from students indicate how students integrated their practice outside of class:

I learned that there is not just one way to be a leader and that we all have different areas and strengths that we each contribute to as a whole. Learning to want to challenge the way I conducted my weekly routines. It became more of a way to challenge myself than a need to for this class (32).

I integrated these two strategies from the reading by: basing my decisions on if they would set a good example to others and expressing my values to others in order for them to understand who I am and what I believe in. (7)

Another student reflected on how the practice they focused on promoted a sense of togetherness, which was important in many contexts: 
I learned that we need to feel connected to others and, in turn, they do to us because greatness is never achieved alone. Encouraging the Heart is the leadership practice that connects us with one another. It signals and documents that we're in "this" together whatever this project, program, campaign, neighborhood, congregation, or whatever it is may be (26).

Yet another student specifically reflected about how they intend to integrate thepractice of modeling the way as a habit in their life:

I'll definitely be taking the reflection part of this project with me in continually trying to make this a habitual behavior, as well as the simple act of picking up trash. It isn't something that I consciously avoid doing, but is also not my first thought or inclination to do. Through these three weeks though, I have seen this innate inclination showing its face more in my daily life. I like this improvement of my attention to the surrounding world and personal responsibility for it, and I hope to continue working this basic action into my days both in familiar and new areas (41).

Human Dimension. The human dimension domain of learning involves learning about oneself and others. Through this domain, students may learn things about themselves that enables them to function more effectively with others. Students may also experience a new understanding of others and how and why they act the way they do (the human significance of what they are learning). One student reflected on realizing how their actions can affect others:

I knew I was a leader but I never knew the importance of having such a strong and nice heart. By slightly changing the way I do things I was able to build relationships and have a very good dynamic with the sophomore class below me (35).

Other students focused on their ideas of what it meant to become a better leader. Student 63 stated "What makes a good leader is a person that has the ability to step back and say I need to do this to become better" (63). And, student 58 wrote "Developing as a leader for me will look different than anyone else and I am okay with that" (58).

Some other students focused on how to deal with frustrations of being a leader and how to navigate setbacks including student 45 who wrote "... being able to stay positive and shake off the mistakes is what it takes to be a leader." And, student 26 reflected in the following way:

The only setback I somewhat had was finding more courage within myself to be more encouraging and I was able to handle this by looking at what behaviors I wanted tohave and realizing that I had to do this to obtain this behavior as part of who I am.

Another student discussed learning about themselves due to feedback fromtheir accountability partner in this assignment:

The best feedback I received from her is that I have to focus on what the person I am talking to really needs to hear to help push them forward. I cannot just reach into my 
mind for a standard sentence, I need to really pay attention and focus on the individual (64).

Caring. Student reflections revealed the PLTA assignment motivated them to learn more and energized them to be engaged in the leadership behavior more frequently. Student 62 wrote: "now that I have realized how much of a difference encouraging others does for the human heart and mind I will never be the same." And, in reference to receiving a "favorite" through their tweets posted as part of the assignment, one student reflected that "also receiving favorites was able to help encourage myself because it made me feel as if my other classmates and TA were proud of my actions" (7).

One student specifically mentioned how leadership involves caring and this is what they set out to do:

I read this in the reading and it specifically spoke to me, "... [a]nd at the heart of leadership is caring. . . As a relationship, leadership requires a connection between leaders and their constituents over matters, in the simplest sense, of the heart." ... This is what drove me during this assignment. In everything I do I have really been trying to genuinely care and show others that I do care. (26)

One other student realized the value of caring about another individual:

I have realized that they will perform better if they are praised for their hard work, orat least have it acknowledged. . . I did this so that they would know I'm invested in them and care about their success (35).

Learning how to Learn. This domain of learning may result in students developing self-authorship, self-regulation, self-efficacy, resilience, adaptability, and motivation. One student's reflection dealt with the development of self-efficacy as a leader: "I find myself searching for new ways to challenge myself without even realizing it, but I still struggle with challenging others. I find myself a little more confident in stepping out of my comfort zone as well" (1).

And, two students' reflection seemed to highlight the development of resiliency through the assignment: "[Personally developing as a leader] is a process and it takes time. We are constantly learning as individuals and leaders" (33). And, student 1 reflected:

As a leader, I learned that it takes time to develop and sometimes I am going to make mistakes and fail. This is only part of the process because I am constantly learning no matter what. I also learned that as hard as I try, sometimes I just won't become as comfortable with certain aspects of challenging the process, as I would like.

This student further elaborated on how the assignment motivated them in their daily lives: "This assignment really helped with motivating myself by taking what I have learned in class and integrating it into my everyday life" (1). Two students seemed to focus on the notion of self-regulation and the use of reflection for improvement. In the case of student 62, "I feel like it [twitter] was effective, because reflecting on your actions is one of the best ways of 
learning, just like when one reflects on mistakes in order to learn from them." Another student wrote:

I learned that I can develop my leadership skills if I increase my awareness of my behaviors and seek opportunities to take action towards specific goals...Reflecting on my actions is a great way for me to analyze events and learn how to improve them for the future (27).

Influence of Context. In the reflections, students discussed what they did to engage in their behavior over the course of three weeks. Students who had definite contexts to apply through the PLTA could articulate their learning at a higher level and make concrete connections to concepts learned more than students who did not have a defined context. Examples of definite contexts were student organizations, student employment, and other class projects.

Influence of Defined Goals. Students were also asked to develop goals for the PLTA at the beginning of the assignment and then to reflect on how these were achieved or not over the timespan of three weeks. Students who had well-defined goals at the beginning of their PLTA were also able to better articulate their learning at a higher level and make concreteconnections to their learning more than students who did not have well-defined goals.

\section{Conclusions \& Recommendations}

Fink's (2013) taxonomy of significant learning is a roadmap for helping leadership educators ground leadership education in principles and practices of evidence-based learning (Owen, 2015a). The taxonomy includes six domains of learning: foundational knowledge, application, integration, human dimension, caring, and learning how to learn. Through a content analysis of student reflections about a PLTA assignment in an undergraduate personal leadership course, types of significant learning were measured (Fink, 2013).

Students' reflections provided evidence that all six types of learning were achieved through the PLTA. This research is an example of evidence-based practice that demonstrates how a pedagogy can foster significant learning in students. Though all types of learning were found among the 24 reflections, the researchers did not examine how many of the reflections each contained evidence of all six types of learning. As Fink (2003) suggests the more kinds of learning that exists within an experience, the more significant the learning can be, further research could examine whether the experience promoted significant learning for each individual. Furthermore, specific variables like backgrounds and experiences of students could be examined to assess how these impacted their significant leadership learning.

A characteristic of significant learning is that it can result in the student developing selfauthorship, self-regulation, critical self-reflection, self-efficacy, resilience, adaptability, and selfmotivation (Fink, 2003). Further research could also examine the effects of this assignment on student's development of these concepts.

Two findings outside of measuring the six domains of learning resulted from the content analysis of the student reflections. Students who had defined goals and more defined contexts 
could better articulate and reflect and illustrate their kinds of learning. The researchers did not ask students specifically to reflect on their kinds of learning they achieved; they completed reflections about their experience and the researchers made sense out of their reflections as to what kinds of learning were achieved. It is recommended that leadership educators who want to utilize an assignment like this be purposeful in getting students to have specific, defined goals and to apply the learning of their practice to a more defined context such as work experience, student organizations, or other class projects.

Active learning techniques are used by leadership educators to enhance the quality of learning for the leadership learner. It has been recommended that active learning techniques be used to assess learning both formatively and summatively (Owen, 2015a). The PLTA, which was the focus of this study, allowed for assessment of learning during the process (formatively) through the use of micro-reflections by the students using Twitter. Students "tweeted" daily about their experiences developing their chosen practice, one of Kouzes and Posner's five practices of exemplary leadership, which captured how they were engaged with the practice. The "tweets" were not analyzed for this study because after names were removed for analysis of the reflections, there was not a way to access the specific tweets of the individuals whose reflections were analyzed for this study. A recommendation for further study would be to analyze the "tweets" made by students throughout the three-week time period to gain a more holistic view of the learning taking place through this pedagogy.

\section{References}

Abrahamson, M. (1983). Social research methods. Englewood Cliffs, NJ: Prentice Hall.

Ambrose, S. A., Bridges, M. W., DiPietro, M., Lovett, M. C., \& Norman, M. K. (2010). How learning works: Seven research-based principles for smart teaching. John Wiley \& Sons.

Andenoro, A. C., Allen, S. J., Haber-Curran, P., Jenkins, D. M., Sowcik, M., Dugan, J. P., \& Osteen, L. (2013). National leadership education research agenda 2013-2018: Providing strategic direction for the field of leadership education. Retrieved from Association of Leadership Educators.

Berg, B. L. (2001). Qualitative research methods for the social sciences. Needham Heights, MA: Allyn \& Bacon.

Bloom, B. S. (Ed.). (1956). Taxonomy of educational objectives: The classification of educational goals, by a committee of college and university examiners. New York: D. McKay.

Borg, W. R., \& Gall, M. D. (1989). Educational research: An introduction (5 ${ }^{\text {th }}$ Ed.). White Plains, NY: Longman.

Brungardt, C. (1997). The making of leaders: A review of the research in leadership development and education. Journal of Leadership \& Organizational Studies, 3(81), 81-95. Doi: $10.1177 / 107179199700300309$ 
Bryman, A. (2012). Social research methods. $4^{\text {th }}$ Ed. New York: Oxford Press.

Charon, R. (2001). Narrative medicine: A model for empathy, reflection, profession, and trust. Journal of the American Medical Association, 286(15), 1897-1902.

Daloz Parks, S. (2005). Leadership can be taught. Boston, MA: Harvard Business School Press.

Day, D. V., Harrison, M. M., \& Halpin, S. M. (2009). An integrative approach to leader development: Connecting adult development, identity, and expertise. New York, NY: Routledge.

Erlandson, D., Harris, E. L., Skipper, B. L., \& Allen, D. S. (1993). Quality criteria for a naturalistic study. Doing naturalistic inquiry: A guide to methods, 131-162.

Fink, L. D. (2003). Creating significant learning experiences: An integrated approach to designing college courses ( $1^{\text {st }}$ ed.). San Francisco, CA: Jossey-Bass.

Fink, L. D. (2013). Creating significant learning experiences: An integrated approach to designing college courses ( ${ }^{\text {nd }}$ ed.). San Francisco, CA: Jossey-Bass.

Fraenkel, J. R., \& Wallen, N. E. (2012). How to design and evaluate research in education ( $8^{\text {th }}$ Ed.). New York, NY: McGraw-Hill.

Jenkins, D. (2012). Exploring signature pedagogies in undergraduate leadershipeducation. Journal of Leadership Education, 11(1), 1-27.

Kouzes J. M. \& Posner, B. Z. (2014). The student leadership challenge: Five practicesfor becoming an exemplary leader. ( $2^{\text {nd }}$ ed.) San Francisco, CA: Wiley.

Lincoln, Y. S., \& Guba, E. G. (1985). Naturalistic inquiry. Newbury Park, CA: Sage.

Merriam, S. B. (2009). Qualitative research: A guide to design and implementation (3rded.). San Francisco, CA: Jossey-Bass

Miles, M. B., \& Huberman, M. A. (1994). Qualitative analysis: An expanded sourcebook. (2 ${ }^{\text {nd }}$ Ed.) Thousand Oaks, CA: Sage.

Owen, J. E. (2015a). Transforming leadership development for significant learning. New Directions for Student Leadership, 145, 7-17. doi: 10.1002/yd.20120

Owen, J. E. (2015b). Integrative and interdisciplinary approaches to leadership development. New Directions for Student Leadership, 145, 49-58. doi: 10.1002/yd.20123

Palmer, P. J., \& Zajonc, A. (2010). The heart of higher education: A call to renewal. San Francisco, CA: Jossey-Bass. 
Preskill, S., \& Brookfield, S. D. (2009). Learning as a way of leading: Lessons from the struggle for social justice. San Francisco, CA: Jossey-Bass.

Roberts, D. C. (2007). Deeper learning in leadership. San Francisco, CA: Jossey-Bass.

Scanlon, J. M., Care, W. D., Udod, S. (2002). Unravelling the unknowns of reflection in classroom teaching. Journal of Advanced Nursing, 38(2), 136-143.

Strauss, A. L. (1987). Qualitative analysis for social scientists. New York: Cambridge University Press.

Vaill, P. B. (1998). Spirited leading and learning: Process wisdom for a new age. San Francisco, CA: Jossey-Bass.

\section{Author Biographies}

Summer F. Odom is an Assistant Professor in the Department of Agricultural Leadership, Education, \& Communications at Texas A\&M University. She teaches courses in personal and professional leadership. Her research interests include leadership and life skill capacity building of young adults and assessment and evaluation of leadership pedagogy.

summerodom@tamu.edu

Valerie Mckee is the Leadership Programs Coordinator for the Center for Leadership within the Institute of Food and Agricultural Sciences at the University of Florida (UF). In her role, Valerie works to develop leadership capacity within Florida's agriculture industry by facilitating leadership trainings and providing support to the Center's leadership programs. vmckee@ufl.edu

Allison L. Dun is a graduate assistant and Ph.D. student within the Department of Agricultural Leadership, Education, and Communications at Texas A\&M University. Her research interests include the intersection of curricular and co-curricular leadership programs, student leader motivation and developmental readiness, and the development of leaders who lead other leaders. aldunn@tamu.edu 